\title{
Avaliação da retenção de sedimentos pela vegetação ripária pela caracterização morfológica e físico-química do solo
}

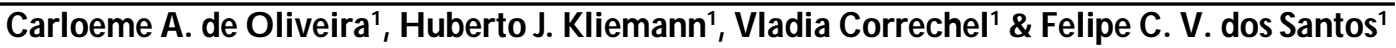

\begin{abstract}
RESUMO
O objetivo do estudo foi avaliar a retenção de sedimentos por meio da caracterização morfológica e físico-química de um Latossolo Vermelho distrófico ao longo de uma transeção de $204 \mathrm{~m}$ demarcada no sentido do declive, iniciada no meio da encosta cultivada com algodão em sistema de preparo convencional e finalizada no interior da mata ciliar localizada a jusante da área cultivada em Panamá, GO. Todas as amostras de solo foram coletadas ao longo da transeção em camadas de 0-5, 5-10 e 10-20 $\mathrm{cm}$. $\mathrm{Na}$ mata ciliar foram abertas quatro trincheiras para avaliação morfológica dos perfis de solo. A descrição morfológica das duas primeiras trincheiras abertas na entrada da mata indicou a presença de camadas de material não pedogenizado sobre o horizonte $A$, proveniente de sedimentos carreados da lavoura para a mata ciliar por processos erosivos. A interpretação das avaliações morfológicas dos perfis, associada aos resultados de análises do solo, revela que o cultivo intensivo altera os atributos físicos e químicos, especialmente a agregação e os teores de matéria orgânica e Ca.
\end{abstract}

Palavras-chave: sedimentação, erosão hídrica, áreas preservadas

\section{Assessment of the retention of sediments by riparian forest by morphological and physico-chemical characterization of soil}

\begin{abstract}
This study aimed to assess the efficiency of a riparian forest to retain runoff sediments from cropped areas by means of morphological and physico-chemical characterization of a Typic Haplustox Cerrado soil along a $204 \mathrm{~m}$ transect. All soil samples were collected from layers of $0-5,5-10$ and $10-20 \mathrm{~cm}$ on the cropped areas, ending on a riparian forest. The studied areas w ere cropped with cotton under conventional tillage system. For the morphological descriptions of soil profiles in the riparian forest, four trenches were opened. The first two descriptions done at the entrance of the forest showed the presence of nonpedogenic material over the $A$ horizon, originated from sediments dragged off the cropped areas to the forest through erosive processes. Morphological assessment of soil profiles associated to soil analysis shows that intensive cropping changes physical and chemical attributes, especially aggregation indices, as well as organic matter and Ca contents.
\end{abstract}

Key words: soil sediments, water erosion, preserved areas 


\section{INTRODUÇÃO}

Na região de Cerrado, os Latossolos correspondem não só a 46\% dos solos de ocorrência nesse bioma, mas também representam a zona de maior potencial de biodiversidade. Ao estudar o solo em condição natural, tornam-se conhecidas as características e propriedades do solo e a dinâmica da água em que a vegetação original se desenvolve (Brasil, 2002).

O bioma Cerrado que cobria cerca de dois milhões de $\mathrm{km}^{2} \mathrm{da}$ superfície do território nacional, foi destruído e substituído por agricultura e silvicultura (Durigan et al., 1998) por ação antrópica, mas o clima, o material de origem, a forma da vertente, os processos geomorfológicos e de infiltração de água, atuam de maneira conjunta e são responsáveis pela formação de solos diferenciados em uma mesma vertente.

Nas últimas décadas o estudo pedológico da vertente por meio de topossequências de solos tem apontado para a influência de outros fatores de formação no desenvolvimento das características e propriedades dos solos, mas ainda são poucos os trabalhos sobre as propriedades físico-hídricas do solo e a morfologia junto à análise estrutural dos solos para determinar as transições dos atributos dos solos presentes e caracterizar a dinâmica do meio físico no qual a vegetação local está inserida e pelo qual é influenciada (Brown et al., 2005; Cheng et al., 2002).

Considerando que a área ocupada por culturas graníferas (soja, milho, sorgo) tem aumentado em especial na região Centro-Oeste (Santos et al., 2010) e que a erosão hídrica nas regiões tropicais é considerada o principal processo de degradação da terra, sobretudo quando cultivada de modo intensivo (Lal \& Stewart, 1990) o fluxo de energia da enxurrada se inicia com o impacto da água sobre o solo, que promove o desprendimento e o transporte de partículas para regiões que propiciam a interceptação de sedimentos.

Essas regiões deveriam ser ocupadas pela mata ciliar ou vegetação ripária que, por estar situada entre dois ecossistemas (o terrestre e o aquático) tem, por natureza, a importante função de regular a geração de energia e de nutrientes de um ecossistema para outro.

A vegetação ripária desempenha papel de elevada importância ambiental (Jacobs \& Voguel, 1998), seja por sua capacidade de recarregar aquíferos, de manutenção da qualidade da água, de reduzir as taxas de erosão e assoreamento dos rios ou, principalmente, por sua importância para a manutenção da biodiversidade (Richie \& Mcarty, 2003). Além disso, protege o solo contra a erosão pela retenção física das raízes, pela diminuição do impacto da água sobre o solo através das folhas e do caule e pelo recobrimento do solo por meio da formação da camada de serrapilheira. Por todos esses fatores espera-se que, quanto maior o recobrimento vegetal menor seja a perda de solo por erosão (Brasil, 2002; Sharma \& Shakya, 2006).

De acordo com Wang et al. (2005), quanto maior o estado de deterioração de uma mata ciliar menor sua eficiência em reter sedimentos, devido à sua menor capacidade de reduzir a velocidade de transporte de partículas, ou seja, menor controle hidrológico. Os trabalhos desenvolvidos por Mckergon et al. (2003) e Lowrance et al. (1997) mostram que a vegetação ripária contribui para melhorar a qualidade da água, a remoção de sedimentos em suspensão de diversas formas de nitrogênio, fósforo e potássio, por processos químicos, físicos e biológicos, protegendo os rios de fatores poluentes por filtragem (Osborne \& Kovacic, 1993).

Trabalhos mostram que, quanto mais intensivo o uso do solo mais significativas são as alterações causadas às suas propriedades físico-químicas e biológicas, predispondo-o à erosão hídrica, propiciando condições desfavoráveis ao desenvolvimento radicular, em especial quando compara-se, estas alterações, ao solo sob uso intensivo e sob condições de vegetação natural (Wu et al., 2003; Karlen et al., 2003; Araújo et al., 2004; Stone \& Guimarães, 2005; Figueiredo et al., 2009; Corrêa et al., 2010).

O objetivo deste trabalho foi avaliar a eficiência da mata ciliar na retenção de sedimentos por meio da caracterização morfológica e físico-química de um Latossolo Vermelho distrófico em transeção iniciada em área cultivada com algodão em sistema de preparo convencional e finalizada no interior da mata ciliar.

\section{Material e MÉTOdos}

Em Panamá, GO, o estudo foi desenvolvido em uma lavoura de algodão cultivada em sistema de plantio convencional (SPC) há 12 anos, em um Latossolo Vermelho distrófico. A área, localizada a $18^{\circ} 09^{\prime} 22^{\prime \prime} \mathrm{S}, 49^{\circ} 26^{\prime} 24^{\prime \prime} \mathrm{W}$, possui declive médio de $8 \%$ ao longo da encosta. À jusante da lavoura há uma faixa de 44 m de largura com vegetação ripária.

O clima da região (tipo Aw pela classificação de Köppen) é caracterizado como tropical úmido, com duas estações bem definidas (úmida no verão e seca no inverno) e chuvas concentradas entre dezembro a março, com precipitação média anual de 1200 a $1800 \mathrm{~mm}$ cujas temperaturas médias variam entre 18 a $30{ }^{\circ} \mathrm{C}$ (ACEG, 2002).

A amostragem do solo foi feita ao longo de uma transeção de $204 \mathrm{~m}$ demarcada no sentido do declive após a colheita do algodão, iniciada partindo-se do meio da encosta na área cultivada (160 m de comprimento) até o final da mata ciliar (44 m de comprimento) na margem do curso de água. Na área cultivada foram coletadas amostras de solo em cinco pontos e, na mata ciliar, quatro pontos e abertas quatro trincheiras.

Em cada ponto de amostragem foram coletadas amostras deformadas com o uso de trado, blocos de terra $(5 \times 5 \times 5 \mathrm{~cm}) \mathrm{e}$ amostras indeformadas com um extrator de anéis volumétricos $\left(98 \mathrm{~cm}^{3}\right)$. As amostras foram retiradas nas camadas 0-5, 5-10 e $10-20 \mathrm{~cm}$.

A textura do solo foi determinada pelo método do densímetro de Bouyoucos com $\mathrm{NaOH}$ (EMBRAPA, 1997) e o volume total de poros (VTP) conforme a eq. (1):

$$
\mathrm{VTP}=\left(1-\left(\frac{\mathrm{Ds}}{\mathrm{Dp}}\right)\right) \cdot 100
$$

em que: Ds é a densidade do solo $\left(\mathrm{kg} \mathrm{cm}^{-3}\right)$ e Dp é a densidade de partícula $\left(\mathrm{kg} \mathrm{cm}^{-3}\right)$ Obteve-se a macroporosidade (Ma) pela 
diferença entre a VTP e a microporosidade (Mi), esta determinada pelo conteúdo de água correspondente à tensão de $6 \mathrm{kPA}$.

A Ds foi mensurada pelo método do anel volumétrico (EMBRAPA, 1997), a umidade gravimétrica (U) definida com base em peso e a condutividade hidráulica (Ko) estimada pela equação de Darcy-Willians para fluxo de água no solo.

Os agregados maiores ou iguais a $2 \mathrm{~mm}$ (agreg), diâmetro médio ponderado (DMP) e diâmetro médio geométrico (DMG) foram definidos conforme EMBRAPA (1997). A resistência do solo à penetração mecânica (RP) foi estimada por meio de penetrometrias realizadas com penetrômetro de impacto modelo Planalçucar com três repetições por ponto (Stolf et al., 1983).

Determinaram-se os atributos químicos de acordo com os procedimentos descritos em EMBRAPA (1997). O pH foi determinado em $\mathrm{CaCl}_{2}$, a matéria orgânica do solo (MOS) oxidada, o fósforo $(\mathrm{P})$ e o potássio $(\mathrm{K})$ trocáveis extraídos pelo método Mehlich-I e analisados por colorimetria e fotometria de chama, respectivamente.

Os teores de cálcio $(\mathrm{Ca})$ e magnésio $(\mathrm{Mg})$ trocáveis foram determinados por extração com $\mathrm{KCl} \mathrm{N}$ e analisados por absorção atômica, enquanto a saturação por bases (V) foi determinada pela relação entre a soma dos valores de cátions básicos trocáveis e a soma dos cátions totais.

Fez-se a descrição morfológica dos perfis de solo seguindose os procedimentos do IBGE (2007), em trincheiras abertas a 4, 14, 24 e $34 \mathrm{~m}$, a partir da entrada da mata até o final da encosta, na margem do rio.

O delineamento utilizado foi o inteiramente casualizado e os resultados submetidos à análise de variância e teste Tukey a $5 \%$ de probabilidade, para comparação de médias usando-se o programa SAS (Statistical Analysis System).

\section{RESULTADOS E DISCUSSÃO}

De acordo com as descrições morfológicas das trincheiras abertas na entrada da mata e dos resultados das análises físicoquímicas (Tabela 1), foi possível verificar que nos primeiros metros da entrada da mata ocorreu retenção de sedimentos (camada de material não pedogenizado), sobrepostos ao horizonte A.

Na primeira trincheira, aberta a $4 \mathrm{~m}$ da entrada da mata, foram identificadas duas camadas de sedimento com espessura de 8 e $14 \mathrm{~cm}$, enquanto na segunda trincheira, a $14 \mathrm{~m}$ da entrada da mata, apenas uma camada de sedimento com espessura de 11 $\mathrm{cm}$; nas terceira e quarta trincheiras, localizadas, respectivamente, a 24 e $34 \mathrm{~m}$ da borda da mata, o horizonte A se apresentava não soterrado.

A descrição morfológica das trincheiras permitiu classificar as camadas superficiais de sedimentos, com base na observação de cor e caracterização da estrutura; os sedimentos apresentaram cor relativamente mais clara com o matiz vermelho mais intenso, porém a cor do perfil, quando úmido, é bastante homogênea.

Quanto à estrutura, a camada de sedimentos apresenta estrutura granular muito fina, de grau moderado, devido à presença de microagregados, que se desmancham quando
Tabela 1. Valores médios de características e propriedades do Latossolo Vermelho distrófico na área cultivada com algodão e sob mata ciliar. Teste $F$ e coeficiente de variação (CV \%), sendo $\mathrm{N}=5$ repetições na área cultivada e 4 na mata

\begin{tabular}{|c|c|c|c|c|}
\hline \multirow{2}{*}{$\begin{array}{l}\text { Características e } \\
\text { propriedades físicas } \\
\text { e químicas do solo }\end{array}$} & \multicolumn{2}{|c|}{ Latossolo Vermelho distrófico } & \multicolumn{2}{|c|}{ Teste F } \\
\hline & $\begin{array}{l}\text { Cultivado com } \\
\text { algodão }\end{array}$ & $\begin{array}{l}\text { Sob vegetação } \\
\text { ripária }\end{array}$ & Usos & $\begin{array}{l}\text { CV } \\
\%\end{array}$ \\
\hline $\operatorname{Argila}\left(\mathrm{g} \mathrm{kg}^{-1}\right)$ & $514,00 \mathrm{a}$ & $472,50 \mathrm{~b}$ & $20,12 *$ & 5 \\
\hline Silte $\left(\mathrm{g} \mathrm{kg}^{-1}\right)$ & $372,00 \mathrm{a}$ & $322,50 \mathrm{~b}$ & $11,04 *$ & 11 \\
\hline Areia $\left(\mathrm{g} \mathrm{kg}^{-1}\right)$ & $114,00 \mathrm{~b}$ & $205,00 \mathrm{a}$ & $22,44 *$ & 32 \\
\hline AMG $\left(\mathrm{g} \mathrm{kg}^{-1}\right)$ & $9,99 \mathrm{~b}$ & 14,43 a & $6,75^{*}$ & 37 \\
\hline$A G\left(g ~ k g^{-1}\right)$ & $17,47 \mathrm{~b}$ & 34,31 a & $19,34 *$ & 40 \\
\hline$A M\left(g ~ k g^{-1}\right)$ & $19,41 \mathrm{~b}$ & $42,74 \mathrm{a}$ & $22,35 *$ & 43 \\
\hline$A F\left(g ~ k g^{-1}\right)$ & $32,30 \mathrm{~b}$ & $63,25 a$ & $28,45^{*}$ & 33 \\
\hline $\operatorname{AMF}\left(\mathrm{g} \mathrm{kg}^{-1}\right)$ & $34,84 \mathrm{~b}$ & $50,28 \mathrm{a}$ & $6,66 *$ & 37 \\
\hline $\mathrm{Dp}\left(\mathrm{kg} \mathrm{dm}^{-3}\right)$ & $2,76 a$ & $2,51 b$ & $27,94 *$ & 5 \\
\hline $\operatorname{VTP}\left(\mathrm{m}^{3} \mathrm{~m}^{-3}\right)$ & $0,55 a$ & $0,56 a$ & $0,41 \mathrm{~ns}$ & 4 \\
\hline $\operatorname{Ma}\left(\mathrm{m}^{3} \mathrm{~m}^{-3}\right)$ & $0,05 \mathrm{~b}$ & $0,08 \mathrm{a}$ & $5,15^{*}$ & 52 \\
\hline $\operatorname{Mi}\left(\mathrm{m}^{3} \mathrm{~m}^{-3}\right)$ & $0,50 a$ & $0,48 b$ & $5,63^{*}$ & 5 \\
\hline Ds $\left(\mathrm{kg} \mathrm{dm}^{-3}\right)$ & $1,23 a$ & $1,11 \mathrm{~b}$ & $23,58 *$ & 6 \\
\hline $\mathrm{U}\left(\mathrm{kg} \mathrm{kg}^{-1}\right)$ & $0,26 \mathrm{~b}$ & $0,27 \mathrm{a}$ & $35,49 *$ & 3 \\
\hline $\operatorname{Ko}\left(\mathrm{mm} \mathrm{h}^{-1}\right)$ & $11,53 \mathrm{~b}$ & 224,70 a & $23,51^{*}$ & 107 \\
\hline Agreg (\%) & $66,00 \mathrm{~b}$ & 80,17 a & $15,81^{*}$ & 13 \\
\hline $\mathrm{DMG}(\mathrm{mm})$ & $2,11 b$ & $2,66 a$ & $14,77^{*}$ & 16 \\
\hline $\mathrm{DMP}(\mathrm{mm})$ & $2,13 \mathrm{~b}$ & $2,46 a$ & $16,96 *$ & 9 \\
\hline $\mathrm{RP}(\mathrm{MPa})$ & $2,52 \mathrm{~b}$ & $2,95 \mathrm{a}$ & $15,31^{*}$ & 10 \\
\hline $\mathrm{pH}\left(\mathrm{CaCl}_{2}\right)$ & $5,18 \mathrm{a}$ & $5,15 a$ & $0,05 \mathrm{~ns}$ & 9 \\
\hline MOS $\left(\mathrm{g} \mathrm{dm}^{-3}\right)$ & $46,27 \mathrm{~b}$ & $53,73 a$ & $4,77^{*}$ & 18 \\
\hline$P\left(m g ~ d m^{-3}\right)$ & $13,52 \mathrm{a}$ & 30,89 a & $3,07 \mathrm{~ns}$ & 120 \\
\hline $\mathrm{K}\left(\mathrm{mmol}_{\mathrm{c}} \mathrm{dm}^{-3}\right)$ & $5,22 a$ & $3,86 \mathrm{~b}$ & $4,88^{*}$ & 34 \\
\hline $\mathrm{Ca}\left(\mathrm{mmol}_{\mathrm{c}} \mathrm{dm}^{-3}\right)$ & $25,22 b$ & $60,17 a$ & $19,67^{*}$ & 50 \\
\hline $\mathrm{Mg}\left(\mathrm{mmol}_{\mathrm{c}} \mathrm{dm}^{-3}\right)$ & $10,53 \mathrm{~b}$ & 18,03 a & $11,43^{*}$ & 41 \\
\hline V $(\%)$ & $47,59 a$ & $56,55 a$ & $1,91 \mathrm{~ns}$ & 32 \\
\hline \multicolumn{5}{|c|}{ 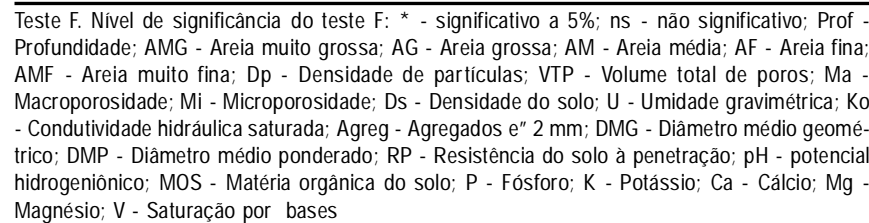 } \\
\hline
\end{tabular}

friccionados contra a mão na presença de água, comportandose como grãos soltos, sem nenhuma orientação e sem a formação de torrão.

O horizonte A soterrado, visível na primeira trincheira, apresenta espessura de $18 \mathrm{~cm}$ e, na segunda trincheira, espessura de $15 \mathrm{~cm}$, caracterizado pela estrutura granular pequena de grau forte com transição abrupta entre os sedimentos e o horizonte A. O horizonte Bw é caracterizado por estrutura em blocos subangulares de grau moderado a forte na primeira trincheira e de estrutura maciça na segunda.

Nas terceira e quarta trincheiras identificou-se a ocorrência de um horizonte $\mathrm{A} / \mathrm{B}$, apresentando estrutura granular de grau moderado; o horizonte A é caracterizado por estrutura em blocos subangulares de grau moderado e o $\mathrm{Bw}$ por estrutura maciça.

Quanto à textura dos perfis observados e apesar de sua textura argilosa predominante, as camadas apresentaram plasticidade e pegajosidade variadas, sugerindo diferenças no teor de argila desses horizontes; nas duas primeiras trincheiras o Bw foi classificado como argiloso; nas demais, o horizonte A foi o que apresentou a maior plasticidade e pegajosidade. 
Em relação às propriedades físico-químicas do solo (Tabela 1), os valores médios de granulometria do solo na área cultivada e sob a mata, mostram que o mesmo possui textura argilosa (EMBRAPA, 1995). As frações argila e silte diferiram com o uso do solo mas não com as profundidades analisadas.

A separação da fração areia total (AT) indica diferenças significativas entre suas frações, em relação aos usos do solo, em especial a fração areia média $\left(\mathrm{AM}=19,41 \mathrm{~g} \mathrm{~kg}^{-1}\right.$ na área cultivada e $\mathrm{AM}=42,74 \mathrm{~g} \mathrm{~kg}^{-1}$ sob a mata). Estes valores podem estar associados à ocorrência de eventos extremos de precipitação resultando em processos de perda de grandes quantidades de terra da área cultivada para o interior da mata. A textura do solo é pouco dependente do uso e manejo do solo, sendo considerado um atributo fixo e resultante de processos pedogenéticos de formação do solo.

De acordo com a Tabela 1, o valor médio de densidade de partículas (Dp) e de densidade do solo (Ds) foi maior no solo sob cultivo que sob a mata, apesar de neste ter sido encontrado maior valor médio de AT.

A análise dos dados mostra que o volume total de poros (VTP) do solo não diferiu com as condições de uso mas que a condutividade hidráulica do solo saturado (Ko) sob mata superou significativamente a encontrada no solo sob cultivo.

Em geral, o VTP ideal para agricultura é representado por 1/ 3 de macroporos (Ma) e 2/3 de microporos (Mi), estabelecendo uma relação $(\mathrm{Ma} / \mathrm{Mi})$ de 0,50 , porém no presente trabalho as relações encontradas $(0,10$ para solo cultivado e 0,17 sob mata) indicam redução na qualidade do solo associada à deterioração das condições da vegetação natural por ação antrópica (Wang et al., 2005).

Os valores médios de Ma encontrados no solo sob mata são menores do que o limite inferior da faixa considerada ideal $\left(0,10\right.$ a $\left.0,16 \mathrm{~m}^{3} \mathrm{~m}^{-3}\right)$, abaixo do qual há limitação ao desenvolvimento das plantas. A diferença encontrada entre os valores de Mi e Ma do solo em cada condição de uso pode ser atribuída ao maior volume de poros grandes formados pela morte de raízes no perfil de solo, formando bioporos no solo sob mata (Brasil, 2002; McKergon et al., 2003).

Apesar do revolvimento do solo na área cultivada proporcionar a formação de $\mathrm{Ma}$, seu efeito é transitório, conforme verificado por Morais (2008) ao avaliar a Ma e Mi de um Latossolo Vermelho distrófico cultivado com algodão antes e depois do preparo de solo em Silvania, GO; por definição (EMBRAPA, 2006), este solo apresenta grande Mi.

A ação antrópica altera a estrutura original do solo reduzindo o VTP com consequências desfavoráveis ao desenvolvimento do sistema radicular das plantas na camada superficial (Stone \& Silveira, 2001). O VTP é influenciado pela Ds, propriedade física que possui relação estreita com a textura e a MOS. Ao reduzir a Ds, o VTP tende a aumentar, em especial a Ma (Assis \& Lanças, 2005, Albuquerque et al., 2001).

$\mathrm{O}$ aumento da densidade do solo (Ds) e a redução da Ma são devidos à compactação causada pelo trânsito de máquinas e implementos agrícolas utilizados no plantio da safra de verão, quando a umidade do solo é elevada (Tormena et al., 2004; Albuquerque et al., 2001). Este fato explica a diferença entre os valores de Ds $\left(1,23 \mathrm{~kg} \mathrm{dm}^{-3}\right.$ na área cultivada e $1,11 \mathrm{~kg} \mathrm{dm}^{-3} \mathrm{na}$ mata) encontrados no presente trabalho, embora esses valores estejam abaixo daqueles considerados restritivos $\left(1,25 \mathrm{~kg} \mathrm{dm}^{-3} \mathrm{e}\right.$ $1,35 \mathrm{~kg} \mathrm{dm}^{-3} \mathrm{em}$ Latossolo Vermelho-Escuro muito argiloso e $1,27 \mathrm{~kg} \mathrm{dm}^{-3}$ para solos argilosos) para a infiltração de água e crescimento radicular das plantas, relatado na literatura (Medina, 1985; Alvarenga et al., 1996; Arshad et al., 1996).

Os valores médios de condutividade hidráulica do solo saturado (Ko) diferem entre os usos do solo. Este resultado pode estar refletindo a maior atividade biológica na mata se comparado ao solo sob cultivo, visto que ela promove a redistribuição de água no solo (Assis \& Lanças, 2005; Borges et al., 2009), a maior Ma e menor Ds, indicando melhor qualidade estrutural do solo, fato confirmado pelos valores médios dos índices de agregação do solo (Tabela 1), que diferem entre os solos sob os diferentes usos; entretanto, em geral este solo, seja em área cultivada ou sob mata, apresenta índices de agregação superiores aos encontrados por Morais (2008). O maior teor de MOS presente no solo sob mata explica esta melhor condição de agregação encontrada (Pedrotti et al., 2003) associada às condições de maior Ma, menor Ds e Dp, e maior atividade biológica, encontradas no solo sob mata.

Em relação ao índice de resistência do solo à penetração mecânica (RP), foram encontrados valores médios de 2,52 MPa na área cultivada e de $2,95 \mathrm{MPa}$ sob a mata, dentro da faixa considerada moderada (2,0 a 4,0 MPa) por Arshad et al. (1996) mas acima do valor (2,0 MPa) crítico para o desenvolvimento radicular da maioria das culturas. Entretanto, os níveis críticos de RP variam com o tipo de solo, com a espécie cultivada, com a Ds, com o teor de MOS e de umidade do solo (Magalhães et al., 2001, Tormena et al., 2004).

A RP não diferiu apenas entre os usos do solo, mas também com as profundidades avaliadas. Na camada de $5-10 \mathrm{~cm}$ foi encontrado um valor médio de RP $=2,90 \mathrm{MPa}$ (Figura 1), associado às práticas de preparo do solo e manejo do algodoeiro, que chega a receber até 15 pulverizações durante o ciclo.

Magalhães et al. (2001) estudaram a RP de um Latossolo Vermelho distrófico sob pastagem e observaram que a época da amostragem é essencial na interpretação dos resultados, pois na época da seca a resistência é cerca de três vezes superior àquela encontrada na época das chuvas.

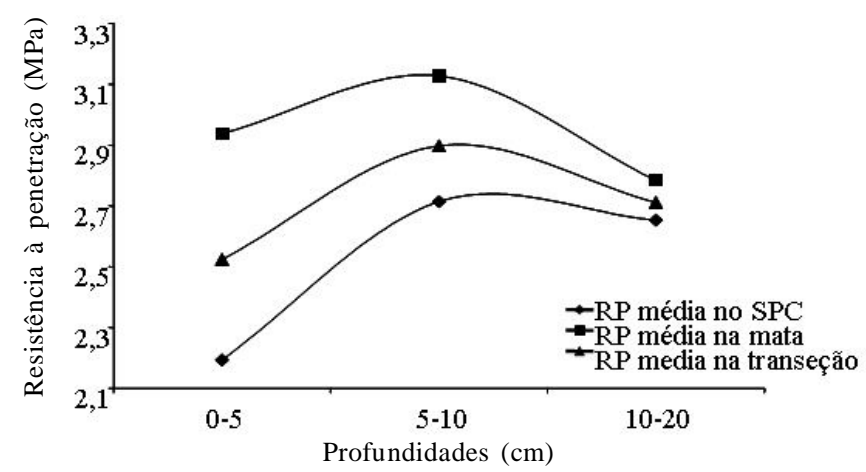

Figura 1. Valores médios de resistência à penetração mecânica (RP) para o Latossolo Vermelho distrófico na área cultivada em sistema de preparo convencional (SPC), sob vegetação ripária (mata) e na transeção de amostragem no sentido do declive. Umidade média do solo no SPC $=0,26 \mathrm{~kg} \mathrm{~kg}^{-1}$ e na mata $=0,27 \mathrm{~kg} \mathrm{~kg}^{-1}$ 
Outras propriedades físicas do solo que diferiram entre as profundidades analisadas, foram o VTP e a Mi, que apresentaram redução significativa com o aumento da profundidade (valores médios de $\mathrm{VTP}=0,57 ; 0,56$ e $0,54 \mathrm{~m}^{3} \mathrm{~m}^{-}$ ${ }^{3}$ e de $\mathrm{Mi}=0,51 ; 0,50$ e $0,48 \mathrm{~m}^{3} \mathrm{~m}^{-3}$ nas camadas $0-5,5-10$ e $10-20$ $\mathrm{cm}$, respectivamente).

Em referência às propriedades químicas do solo, os valores de $\mathrm{pH}$ variaram de 5,15 no solo sob mata a 5,18 na área cultivada, caracterizando uma acidez média, que não diferem entre os usos do solo nem entre as profundidades analisadas. Entretanto, em solos com $\mathrm{pH}$ inferior a 5,5 o algodoeiro pode sofrer uma série de problemas nutricionais que limitam sua produtividade (EMBRAPA, 2001).

Os valores médios de cálcio $(\mathrm{Ca})$ e magnésio $(\mathrm{Mg})$ encontrados na área cultivada $\left(\mathrm{Ca}=25,22 \mathrm{mmol}_{\mathrm{c}} \mathrm{dm}^{-3} \mathrm{e} \mathrm{Mg}=\right.$ $10,53 \mathrm{mmol}_{c} \mathrm{dm}^{-3}$ ) é considerado baixo e médio, respectivamente, conforme os critérios de interpretação descritos em Morais (2008), enquanto os valores médios encontrado na mata $\left(\mathrm{Ca}=60,17 \mathrm{mmol}_{\mathrm{c}} \mathrm{dm}^{-3} \mathrm{e} \mathrm{Mg}=18,03 \mathrm{mmol}_{c}\right.$ $\mathrm{dm}^{-3}$ ) são considerados elevados.

Segundo Ferreira \& Carvalho (2005) a cultura do algodoeiro é sensível à acidez e à presença de alumínio trocável, além de exigente em $\mathrm{Ca}$, que é essencial para o desenvolvimento radicular.

Em relação ao teor de potássio (K) trocável, a Tabela 1 mostra que o solo cultivado apresentou maior concentração desse elemento no solo quando comparado ao solo sob mata, mas Ferreira \& Carvalho (2005) mostram que as maiores produtividades da cultura do algodoeiro foram obtidas quando os teores de $\mathrm{K}$ do solo se encontravam entre 2 e $3 \mathrm{mmol}_{\mathrm{c}} \mathrm{dm}^{-3}$. O teor de matéria orgânica no solo (MOS) variou de 46,27 $\mathrm{g} \mathrm{dm}^{-3}$ (área cultivada) a 53,73 $\mathrm{g} \mathrm{dm}^{-3}$ (mata), considerados valores elevados, de acordo com as classes de suficiência propostas em Sousa \& Lobato (2004).

Entre as propriedades químicas somente os valores médios de $\mathrm{pH}, \mathrm{P} \mathrm{e} \mathrm{Mg}$ não diferiram entre as profundidades analisadas. A MOS foi maior nas camadas superficiais $0-5 \mathrm{~cm}\left(56,53 \mathrm{~g} \mathrm{dm}^{-3}\right)$ e $5-10 \mathrm{~cm}\left(56,12 \mathrm{~g} \mathrm{dm}^{-3}\right)$, diminuindo significativamente na camada 10-20 cm (42,11 $\left.\mathrm{g} \mathrm{dm}^{-3}\right)$, comportamento este, também observado em relação ao teor de $\mathrm{K}$ trocável no solo, que mostrou uma redução de $7,36 \mathrm{mmol}_{\mathrm{c}} \mathrm{dm}^{-3}$ na camada $0-5 \mathrm{~cm}$ para $2,71 \mathrm{mmol}_{\mathrm{c}} \mathrm{dm}^{-3}$ na camada $10-20 \mathrm{~cm}$.

Tais resultados são corroborados pelos de Alcântara \& Ferreira (2000) que encontraram duas vezes mais K na camada $0-10 \mathrm{~cm}$ em relação à camada $10-20 \mathrm{~cm}$ em um Latossolo Vermelho distrófico argiloso. As maiores concentrações de $\mathrm{Ca}$ (55,78 $\left.\mathrm{mmol}_{\mathrm{c}} \mathrm{dm}^{-3}\right)$ e $\mathrm{Mg}\left(17,22 \mathrm{mmol}_{\mathrm{c}} \mathrm{dm}^{-3}\right)$ foram encontradas na camada $10-20 \mathrm{~cm}$ e as menores na de 5-10 $\mathrm{cm}\left(\mathrm{Ca}=27,68 \mathrm{mmol}_{\mathrm{c}}\right.$ $\left.\mathrm{dm}^{-3} \mathrm{e} \mathrm{Mg}=10,81 \mathrm{mmol}_{\mathrm{c}} \mathrm{dm}^{-3}\right)$.

Apesar do valor médio de $\mathrm{P}$ encontrado no solo sob mata ser 2,3 vezes maior do que o encontrado na área cultivada, estes valores não diferem entre si devido à grande variabilidade desse elemento no solo, independente do uso e da profundidade analisada.

O elevado coeficiente de variação $(\mathrm{CV}, \%)$ associado ao teor de $\mathrm{P}$ do solo pode ser explicado pelo modo de aplicação e baixa mobilidade do $\mathrm{P}$ no solo. Os teores médios de $\mathrm{P}$ encontrados $\left(13,52 \mathrm{mg} \mathrm{dm}^{-3}\right.$ na área cultivada e $30,89 \mathrm{mg} \mathrm{dm}^{-3}$ sob a mata) podem ser considerados elevados quando analisados por critérios descritos em Morais (2008).

A maior concentração de P no solo sob mata pode estar relacionada à ocorrência de processos erosivos que carrearam sedimentos da área cultivada para o interior da mata. Além disso, sob a mata há reciclagem de nutrientes e aporte de elementos ao solo; na área cultivada a adubação fosfatada é realizada a cada plantio.

Em geral, o manejo da lavoura apresenta condições adequadas à produção do algodão, mas a elevada concentração de nutrientes no interior da mata associada às camadas de sedimentos identificadas nas duas primeiras trincheiras abertas no interior da mata sugere que os sedimentos transportados pela enxurrada em eventos específicos de erosão hídrica foram retidos de modo eficiente pela vegetação ripária.

\section{CONCLUSÕES}

1. A presença da camada de material não pedogenizado sobre o horizonte A, presente apenas nas duas primeiras trincheiras localizadas na entrada da mata, e os resultados das análises físico-químicas do solo, indicam que os sedimentos carreados pela erosão das áreas à montante, foram retidos pela vegetação ripária.

2. O uso do solo altera propriedades físicas e químicas do solo propiciando redução da RP, da qualidade de agregação do solo e dos teores de MOS e Ca trocável.

\section{AgRADECIMENTOS}

À Fundação de Amparo à Pesquisa de São Paulo (FAPESP), pelo auxílio financeiro concedido ao processo n ${ }^{\circ}$ 2005/59484-0, e aos colegas do grupo de pesquisa em Física e Conservação do Solo da EA/UFG, que contribuíram para a realização deste trabalho.

\section{LITERATURA CITADA}

ACEG - Atlas Climatológico do Estado de Goiás. Goiania: UFG, 2002. 100p.

Albuquerque, J. A.; Sangol, L.; Ender, M. Efeitos da integração lavoura-pecuária nas propriedades físicas do solo e características da cultura do milho. Revista Brasileira de Ciência do Solo, v.25, n.3, p.717-723, 2001.

Alcântara, E. N.; Ferreira, M. M. Efeito de métodos de controle de plantas daninhas na cultura do cafeeiro (Coffea arabica L.) sobre a qualidade física do solo. Revista Brasileira de Ciência do Solo, v.24, p.711-721, 2000.

Alvarenga, R. C.; Costa, L. M. da; Moura Filho, W.; Regazzi, A. J. Crescimento de raízes de leguminosas em camadas de solo compactadas artificialmente. Revista Brasileira de Ciência do Solo, v.20, n.2, p.319-326, 1996. 
Araújo, M. A.; Tormena, C. A.; Inoue, T. T.; Costa, A. C. S. Efeitos da escarificação na qualidade física de um Latossolo Vermelho distroférrico após treze anos de semeadura direta. Revista Brasileira de Ciência do Solo, v.28, n.3, p.495-504, 2004.

Arshad, M. A.; Lowery, B.; Grossman, B. Physical tests for monitoring soil quality. In: Doran, J. W.; Jones, A. J. (ed.). Methods for assessing soil quality. Madison: SSSA/Special publication, 1996. n.49, p.123-141.

Assis, R. L.; Lanças, K. P. Avaliação dos atributos físicos de um Nitossolo Vermelho distroférrico sob sistema plantio direto, preparo convencional e mata nativa. Revista Brasileira de Ciência do Solo, v.29, p.515-522, 2005.

Borges, T. A.; Oliveira, F. A.; Silva, E. M. da; Goedert, W. J. Avaliação de parâmetros fisico-hídricos de Latossolo Vermelho sob pastejo e sob cerrado. Revista Brasileira de Engenharia Agrícola e Ambiental, v.13, n.1, p.18-25, 2009.

Brasil. Ministério do Meio Ambiente. Biodiversidade brasileira: avaliação e identificação de áreas e ações prioritárias para conservação, utilização sustentável e repartição dos benefícios da biodiversidade nos biomas brasileiros. Brasília, Projeto de conservação e de utilização sustentável da diversidade biológica brasileira, PROBIO, 2002. 404p. (Série Biodiversidade, 5)

Brown, A. E.; Zhang, L.; McMahon, T. A.; Western, A. W.; Vertessy, R. A. A review of paired catchment studies for determining changes in water yield resulting from alteration in vegetation. Journal of Hydrology, v.310, p.28-61, 2005.

Cheng, J. D.; Lin, L. L.; Lu, H. S. Influence of forests on water flows ffrom headwater watersheds in Taiwan. Forest Ecology and Management, v.165, p.11-28, 2002.

Corrêa, R. M.; Freire, M. B. G. dos S.; Ferreira, R. L. C.; Silva, J. A. A. da; Pessoa, L. G. M.; Miranda, M. A.; Melo, D. V. M. de. Atributos físicos de solos sob diferentes usos com irrigação no semiárido de Pernambuco. Revista Brasileira de Engenharia Agrícola e Ambiental, v.14, n.4, p.358-365, 2010.

Durigan, G.; Leitão Filho, H. F.; Rodrigues, R. R. Phytosociology and structure of a frequently burnt cerrado vegetation in $\mathrm{SE}$ - Brazil. Flora, v.189, p.153-160, 1998.

EMBRAPA - Empresa Brasileira de Pesquisa Agropecuária. Procedimentos normativos de levantamentos pedológicos. Brasília: SPI, 1995. 101p.

EMBRAPA - Empresa Brasileira de Pesquisa Agropecuária. Centro Nacional de Pesquisas de Solos. Manual de métodos de análise de solo. 2.ed. Rio de Janeiro: Embrapa CNPS, 1997. 212p.

EMBRAPA - Empresa Brasileira de Pesquisa Agropecuária. Manual de Análise de Solo. Dourados: Embrapa Agropecuária Oeste/Embrapa Algodão, 2001. 296p.

EMBRAPA - Empresa Brasileira de Pesquisa Agropecuária. Centro Nacional e Pesquisa em Solos. Sistema brasileiro de classificação de solos. Brasília: Embrapa SPI; Rio de Janeiro: Embrapa Solos, 2006. 306p.

Ferreira, G. B.; Carvalho, M. C. S. Adubação do algodoeiro no cerrado: Com resultados de pesquisa em Goiás e Bahia. Campina Grande: Embrapa Algodão, 2005. 71p. Documentos, 138

Figueiredo, C. C.; Santos, G. G.; Pereira, S.; Nascimento, J. L.; Alves Junior, J. Propriedades físico-hídricas em Latossolo do Cerrado sob diferentes sistemas de manejo. Revista Brasileira de Engenharia Agrícola e Ambiental, v.13, n.2, p.146151, 2009.
IBGE - Instituto Brasileiro de Geografia e Estatística. Manual técnico de pedologia. Rio de Janeiro, 2.ed., 2007. 316p.

Jacobs, J. M.; Voguel, R. M. Optimal allocation of water withdrawals in a river basin. Journal of Water Resources Planning and Management, v.124, n.6, p.142-158, 1998.

Karlen, D. L.; Ditzler, C. A.; Andrews, S. S. Soil quality: Why and how? Geoderma, v.114, p.45-156, 2003.

Lal, R.; Stewart, B. A. Soil degradation: A global threat. Advances in Soil Science, v.11, p.129-172. 1990.

Lowrance, R.; Altier, L. S.; Newbold, J. D.; Schanabel, R. R.; Groffman, P. M.; Denver, J. M.; Correl, D. L.; Gillian, J. W.; Robinson, J. L.; Bronsfield, R. B.; Staver, K. W.; Lucas, W.; Todd, A. H. Water quality functions of riparian buffers in Chesapeak by watersheds. Environmental Management, v.21, n.3, p.687-712, 1997.

Magalhães, R. T.; Kliemann, H. J.; Oliveira, I. P. Evolução das propriedades físicas de solos submetidos ao manejo do sistema barreirão. Pesquisa Agropecuária Tropical, v.31, p.7-13, 2001.

McKergon, L. A.; Weaver, D. M.; Prosser, I. P.; Grayson, R. B.; Reed, A. E. G. Before and after riparian management: Sediment and nutrient exports from a small agricultural catchment, Western Australia. Journal of Hydrology, v.270, n.1, p.253-272, 2003.

Medina, B. F. Influência de dois métodos de preparo de área na compactação de um Latossolo Amarelo. Revista Brasileira de Ciência do Solo, v.9, p.67-71, 1985.

Morais, N. R. Critérios de interpretação da qualidade do solo para a cotonicultura no cerrado goiano. Goiânia: UFG, 2008. 82p. Dissertação Mestrado

Osborne, L. L.; Kovacic, D. A. Riparian vegetated buffer strips in water quality restoration and stream management. Freshwater Biology, v.59, p.243-258, 1993.

Pedrotti, A.; Ferreira, M. M.; Curi, N.; Silva, M. L. N.; Lima, J. M.; Carvalho, R. Relação entre atributos físicos, mineralogia da fração argila e formas de alumínio no solo. Revista Brasileira de Ciência do Solo, v.27, p.1-9, 2003.

Ritchie, J. C.; McCarty, G. W. ${ }^{137} \mathrm{Cs}$ and soil in a small agricultural watershed. Soil \& Tillage Research, v.69, n.1, p.45-51, 2003.

Santos, E. H. M.; Griebeler, N. P.; Oliveira, L. F. C. Relação entre uso do solo e comportamento hidrológico na Bacia Hidrográfica do Ribeirão João Leite. Revista Brasileira de Engenharia Agrícola e Ambiental, v.14, n.8, p.826-834, 2010.

Sharma, R. H.; Shakya, N. M. Hydrological changes and its impacto in water resources of Bagmati watershed, Nepal. Journal of Hydrology, v.11, n.51, p.315-322, 2006.

Sousa, D. M. G.; Lobato, E. Cerrado: Correção do solo e adubação. Planaltina: Embrapa Cerrados, 2004. 416p.

Stolf, R.; Fernandes, J.; Furlani Neto, V. L. Penetrômetro de impacto IAA/Planalsucar-Stolf: Recomendação para seu uso. STAB, v.1, n.3, p.18-23, 1983.

Stone, L. F.; Guimarães, C. M. Influência de sistemas de rotação de culturas nos atributos físicos do solo. Santo Antônio de Goiás: Embrapa Arroz e Feijão. 2005. 15p. Boletim de Pesquisa e Desenvolvimento 
Stone, L. F.; Silveira, P. M. Efeitos do sistema de preparo e da rotação de culturas na porosidade e densidade do solo. Revista Brasileira de Ciência do Solo, v.25, n.2, p.395-401, 2001.

Tormena, C. A.; Friedrich, R.; Pinto, J. C.; Costa, A. C. S.; Fidalski, J. Propriedades físicas e taxa de estratificação de carbono orgânico num Latossolo Vermelho após anos sob dois sistemas de manejo. Revista Brasileira de Ciência do Solo, v.28, n.6, p.1023-1031, 2004.
Wang, X. H.; Yin, C. Q.; Shan, B. Q. The role of diversified landscape buffer structures for water quality improvement in an agricultural watershed, North China. Agricultural Ecosystem And Environment, v.107, n.2, p.381-396, 2005.

Wu, L.; Feng, G.; Letey, J.; Fergunson, L.; Mitchell, J.; McCullough-Sanden, B.; Markegard, G. Soil management effects on the no limiting water range. Geodema, v.114, p.401414, 2003. 